\title{
A hard coat, a tough choice? The effects of host seed morphology and mechanics on the egg laying behaviour of the bruchid beetle, Callosobruchus maculatus.
}

\author{
Adrian M. Goodman ${ }^{\underline{a}}$ and Giddings J. Joseph ${ }^{\underline{a}}$ \\ ${ }^{a}$ University of Lincoln, United Kingdom \\ Available online 27 June 2009.
}

This study investigated whether the egg laying behaviour of Callosobruchus maculatus, an important storage pest of leguminous seed crops, was related to the mechanical properties of the host seed. The hypothesis was that females avoid laying eggs on seeds with particularly tough seed coats and hard cotyledons to reduce the resistance their larvae are subjected to when they bore into the seed to complete their development.

Females were presented with seeds from three leguminous species: Vigna unguiculata, V. angularis and V. radiata. The distribution of oviposition sites on the seed's surface was related to the morphology and mechanical properties of the seed. Vickers microhardness and fracture tests were used to investigate regional variation and compare the properties of seeds with and without eggs adhered to their surface.

There were no significant regional differences in the hardness of the cotyledon material along the longitudinal axis of the seed $(P>0.05)$. However, there were significant differences between the mechanical properties of the seed coat and the cotyledons; in $V$. unguiculata the seed coat was tougher, $1249 \pm 80.8 \mathrm{~J} \mathrm{~m}^{-2}$, than the cotyledons, $402 \pm 30.0 \mathrm{~J} \mathrm{~m}^{-2}(P<0.01)$. There was no significant difference between the hardness or toughness of oviposited seeds compared to seeds left bare; oviposited $V$. unguiculata seeds had a mean hardness of $9.22 \pm 0.458 \mathrm{~kg} \mathrm{~mm}^{-2}$ and nonoviposited seeds $9.11 \pm 0.425 \mathrm{~kg} \mathrm{~mm}^{-2}(P>0.05)$. Mechanical data are discussed in relation to the egg laying behaviour of C. maculatus.

Email Address for correspondence: agoodman@lincoln.ac.uk 